\title{
Persistent Precarity and the Disaster of Everyday Life: Homeless People's Experiences of Natural and Other Hazards
}

\author{
JC Gaillard $^{1,3} \cdot$ Vicky Walters $^{2} \cdot$ Megan Rickerby $^{1} \cdot$ Yu Shi $^{1}$
}

Published online: 16 September 2019

(C) The Author(s) 2019

\begin{abstract}
Knowledge of how homeless people deal with natural hazards and disasters is sparse and there is a remarkable absence of homeless people in policies and practices for disaster risk reduction (DRR). This article aims at filling this gap by exploring the lives of homeless people in two New Zealand cities that are exposed to natural hazards. It shows that natural hazards are of marginal concern to homeless people in comparison to the everyday hazards that they experience and that make their everyday life a disaster in itself. The disaster of everyday life is created and compounded by homeless people's precarious lifeworlds. The article, nonetheless, shows that homeless people's vulnerability to natural hazards remains high as they lack power to control the processes that shape their everyday lives, to prepare for large-scale events, and to be represented in DRR policy. Therefore, the article ultimately argues that disaster policies require greater attention to be paid to the power structures that create persistent precarity and the ways in which this is experienced in everyday life.
\end{abstract}

Keywords Everyday

life $\cdot$ Hazard $\cdot$ Homelessness $\cdot$ New

Zealand $\cdot$ Precarity $\cdot$ Vulnerability

JC Gaillard

jc.gaillard@auckland.ac.nz

1 School of Environment, The University of Auckland, Auckland 1142, New Zealand

2 School of People, Environment and Planning, Massey University, Albany 0632, New Zealand

3 Unit for Environmental Sciences and Management, NorthWest University, Potchefstroom 2520, South Africa

\section{Homeless People in Disasters}

There is an odd inconsistency in disaster studies. On the one hand, there is persistent advocacy emphasizing that the poor are the most vulnerable to natural hazards because of their marginal position in society. On the other hand, there exists a lack of attention given to the poor who struggle at the far edge of the same society. Noteworthy here are homeless people including those who sleep rough or are precariously sheltered for whom accessing resources to sustain their everyday needs as well as means of protection in dealing with natural hazards is most difficult. Our knowledge of how homeless people deal with natural hazards and disasters is sparse and there is a remarkable absence of homeless people in policies and practices for disaster risk reduction (DRR).

Since it was recognized two decades ago by Phillips (1998, p. D18) that we knew "next to nothing about how disasters affect the homeless," a few isolated case studies have emerged. These studies suggest that rough sleepers suffer severely from disasters and that their everyday life and routine is profoundly disrupted. These studies all emphasize that homeless peoples' vulnerability in facing natural and other hazards result from obstructed access to available resources (Phillips 1996; Wisner 1998; Drabek 1999; Cusack et al. 2013; Walters and Gaillard 2014; Vickery 2015, 2017, 2018; Every and Richardson 2017). A small number of other studies have also documented how access to resources only worsens in the aftermath of disasters, thus aggravating the vicious circle of marginalization already observed before the disaster (Phillips 1998; Settembrino 2013, 2015, 2016). Vulnerability to everyday hazards and large-scale disasters reflects homeless people's everyday precarity, destitution, and invisibility and how power and resources are inequitably shared within society. 
It is therefore unsurprising that homeless people are consistently overlooked in international guidelines for DRR such as the Sendai Framework for Disaster Risk Reduction 2015-2030 (UNISDR 2015), as well as in national policies such as in Australia (Every and Thomspson 2014; Every and Richardson 2017), Canada (Sundareswaran et al. 2015), the United States (Edgington 2009), Japan (Wisner 1998), and India (Walters and Gaillard 2014).

The emerging but still sparse evidence provides a rationale for further exploring how homeless people understand and experience hazards and disasters and how this intersects with the existence of precarity in their lives. In this article we explore the lives of homeless people in two cities of New Zealand that are exposed to natural hazards-Christchurch and Wellington. We show that the actual or possible events associated with natural hazards, especially rare ones that stir the attention of DRR policies and actions, is of marginal concern to homeless people in comparison to the everyday hazards that they experience and that are created and compounded by their precarious lifeworlds. Despite this marginal concern, we also show that their vulnerability to natural hazards remains high as they lack the resources and power to control the processes that shape their everyday lives, to prepare for large-scale events, and to be represented in DRR policy. Therefore, we argue that the effectiveness of disaster policies in addressing the vulnerabilities of people living at the margins, such as homeless people, requires greater attention to be paid to the power structures that create persistent precarity and the ways in which this is experienced in everyday life.

\section{Power, Precarity, and Disasters}

Understanding precarity and power relations in society is a prerequisite to understanding hazards and the disasters that can manifest from them as expressed in most of the frameworks designed to assess social vulnerability (Watts and Bohle 1993; Wisner et al. 2004; Wisner et al. 2012). The unequal impact of natural hazards that can result in disasters mirrors different patterns of precarity and vulnerability across society. In this article we use the term precarity to represent the powerlessness and fragility of human existence (Butler 2004) and lifeworlds that are inherently uncertain and instable (Waite 2009).

Vulnerability to disasters reflects how power and resources are distributed among individuals and social groups (Wisner et al. 2004). Power is however a contested concept and one that has stirred much attention from all fields of social sciences (for example, Clegg 1989; Haugaard 2002 for overviews). It manifests at different scales through various forms as well as in multiple directions across various segments of society. Such dynamics of power are all relevant to the study of disasters and DRR. In this article we focus on homeless people's direct lack of power (vulnerability) to seeking protection from natural and other hazards as well as the broader power structures and relations (influence) in society that affect homeless' people direct ability to protect themselves or to seek protection from the more powerful, that is, policymakers, DRR agencies.

In dealing with hazards and disasters, direct power reflects people's ability to live safe lives including securing adequate housing and the ability to meet their daily needs. Those who cannot choose to live safe lives and who are forced to live in hazard-prone areas and often without appropriate resources to ensure their protection are those most vulnerable should a potentially harmful event occur (Winchester 1992; Wisner 1993). Hence, vulnerability results from people's inability to control their everyday life so that disasters usually constitute the extension of ordinary emergencies that occur in their everyday lives (Baird et al. 1975; Maskrey 1989). Power and vulnerability to hazards therefore mirrors access to resources and means of protection. People with a broader range of diverse and sustainable resources have more opportunities to exercise power over the decisions that matter for their survival and well-being. Most often these resources and means of protection are available locally, which explains why in any disaster, some people can evacuate while others cannot and why some houses collapse while others withstand stress (O'Keefe et al. 1976; Hewitt 2007). In the case of homeless people, local resources remain beyond their reach to the extent that the cumulative impacts of everyday hazards often manifest in localized and personalized disasters (Walters and Gaillard 2014).

Those with stronger social, economic, and political position in society are privileged with greater access to resources, which reflects unequal relations of influence and power. On the other hand, those who are vulnerable to natural and other hazards and the frequency and impact of disasters most often stand on the margin of society (Gaillard 2010; Wisner 1993). A common thread among people and groups at the margin of society is that their access to the resources needed to sustain their everyday lives is chronically and detrimentally affected by their relationships with social groups who concentrate power and privilege (Hartmann and Boyce 1983; Blaikie and Brookfield 1987). In extreme cases of marginalization, homeless people cannot even claim access to daily resources and means of protection in dealing with natural and other hazards. Often their very citizenship and identity are not legally and/or socially recognized by the state and/or dominant social groups (Walters and Gaillard 2014). 
The root causes of disasters are therefore structural and beyond the sole ability of those affected to make decisions (Watts and Bohle 1993; Wisner et al. 2004). They are exogenous and ultimately reflect the failure of everyday development and associated policies. Thus, a lack of power not only affects those at the margin when dealing with hazards and disasters but obstructs their everyday access to the resources they require to sustain their daily needs and ensure their well-being (Wisner et al. 2012). Therefore, the most marginalized groups not only suffer in the event of large and rare natural hazards. They deal with a large range of small and frequent, natural or not, hazards that have a devastating and protracted effect on their life. These small hazards and disasters are neglected in disaster policies and practices (Wisner and Gaillard 2009) although a growing body of evidence is showing that their cumulated impact may actually be larger than that of larger events (Lavell 2000; Walters and Gaillard 2014; Global Network for Disaster Reduction 2015).

The following study explores the complex interactions between homeless people's everyday precarity and their vulnerability to natural and other hazards in New Zealand. It considers both homeless people's (in)ability and power to sustain their daily needs and protect themselves and the broader power relations in society that affect, and constrain, their choices and decisions.

\section{Homelessness in New Zealand}

According to Statistics New Zealand, homelessness involves social, political, and physical domains and is defined as "living situations where people with no other options to acquire safe and secure housing: are without shelter, in temporary accommodation, sharing accommodation with a household or living in uninhabitable housing" (Statistics New Zealand 2009, p. 6). Homelessness is by its very definition, a state of precarity, not only in terms of a person's inability to secure adequate shelter but in the multitude of hazards that a homeless person is confronted with on an everyday basis.

Homelessness is a growing problem in New Zealand (Richards 2009; Amore et al. 2013). Census data show that the number of "severely housing deprived" (that is, homeless) people has increased from 28,649 (or $0.8 \%$ of the country's total population) to 41,705 individuals (or $1.0 \%$ of the population) between 2001 and 2013 (Statistics New Zealand 2014). Homelessness primarily affects the largest cities in the country, especially Auckland and Wellington, but is also an increasing concern for smaller regional towns. The large majority of homeless people in New Zealand have long been male individuals who disproportionally represent Māori, Pacific, and Asian communities (Groot 2010). However, most recent trends show an increasing number of families with children being forced to sleep rough too (Richards 2009; Amore et al. 2013).

The increasingly precarious nature of employment opportunities presented to those at the spatial, economic, social, and political margins of society, in conjunction with a volatile housing market, indeed result in housing insecurity for low-income individuals and households. In parallel, the progressive transition from a "welfare" to a "competition" state and associated deinstitutionalization of social services have reduced the amount of state support available to people living at the margin of society (Collins and Kearns 2007; Groot et al. 2017). In consequence, more people resort to couch surfing, sleeping in cars, and rough sleeping, especially in the country's three largest cities of Auckland, Christchurch, and Wellington but also increasingly in medium-size cities (Kearns et al. 1992; Collins 2010).

Homeless people also suffer from negative perceptions from those in other sectors of society (Hodgetts et al. 2012). While the lack of permanent shelter propels homeless people to sleep, drink, and seek entertainment and charity in public spaces, the same people are particularly affected by punitive urban policies that involve the banning of public sleeping, alcohol consumption, and begging (Laurenson and Collins 2007). This situation often results in the arrest and harassment of those sleeping rough. The behaviors of homeless people is hence constructed as a threat to public order, further marginalizing their social position and discouraging dialogue between homeless people and policymakers (Laurenson and Collins 2006), including in DRR.

\section{Methodology}

This article draws upon a field study carried out in two of New Zealand's largest cities, Christchurch (397,000 people) and Wellington (412,000 people), between 2014 and 2016. These two cities have been chosen both for their growing homeless population and significant exposure to a range of diverse natural hazards. Christchurch and Wellington are indeed exposed to earthquakes, tsunami, flooding, storms (including snow storms), landslides, and ash fall from distant volcanoes. Both cities are, in fact, hit by floods and storms on a yearly basis but, between 2010 and 2011, Christchurch was struck by a series of powerful earthquakes that killed 185 people and caused extensive infrastructure damage to the Central Business District (CBD) where many homeless people were spending a lot of their time (Potter et al. 2015). In 2016, another powerful earthquake damaged many building in the $\mathrm{CBD}$ of 
Wellington (Stevenson et al. 2017). Noteworthy is that the largest city in New Zealand, Auckland, that hosts the largest homeless population in the country has been excluded not only because of its less diverse hazardscape but, first and foremost, because of research fatigue noticed by homeless people and local government organizations approached at the onset of this study.

The study used "sensitive" qualitative research often prioritized for research on challenging issues such as disasters (Phillips 2014) and "vulnerable" individuals (Liamputtong 2007). It involved interviews and focus groups with people in a cycle of homelessness, organizations running shelters, and stakeholders of DRR. An initial focus group was run with members of the New Zealand Coalition to End Homelessness (NZCEH) at the end of one of their regular meetings held in Hamilton in November 2014. NZCEH is a consortium of diverse individuals and organizations, including charities, community-based groups, and scholars. The objective of this first focus group was to introduce and refine the contours of the research with members of NZCEH. This initial activity also proved very valuable for providing insight into the main issues faced by shelters, advocacy groups, and homeless people in New Zealand.

Semistructured interviews were eventually conducted with five staff of charities running shelters and two representatives from local Civil Defence Emergency Management groups in Wellington and Christchurch, as well as one official from the Wellington City Council. Specifically, organizations and agencies were asked about the services they provide to support homeless people. They were also asked about their understanding on the main threats and hazards homeless people face in everyday life, whether homeless people are identified and catered for in DRR strategies, whether the city has experienced disasters that affected homeless people, and finally how their organizations responded to the situation and what could be done to improve the safety of homeless people during disasters. These interviews provided an overview of homelessness in the two cities and how the issue is considered, or not considered, in everyday urban initiatives and DRR policies.

One focus group was held in Wellington with six precariously sheltered individuals and another one in Christchurch with seven participants sharing similar backgrounds. The focus group participants included both men and women, who were either homeless at the time of the study, living in a night shelter, or were previously homeless. These focus groups were organized by the staff of two shelters who participated in the first round of interviews. Staff at the shelters identified potential participants and made the first introduction to them about the study and the possibility of participating. On the day of the focus groups people who were interested in participating met with members of the project team in a space provided on the premises of the service organization where the participants visit. The project team explained the project and people were invited to opt-into participating and consent was provided verbally. Participants were offered a NZD 20.00 supermarket voucher for their time. Using premises that were familiar to the participants was intended to help in building trust and enable participants to feel comfortable. During the focus group, participants were asked to individually identify the everyday as well as large and rare hazards in their lives by writing on cards. Participants then collectively discussed and ranked the cards from the most to the least significant.

Participants from each of the focus groups were then invited to participate in individual interviews. Three participants from the Wellington focus group agreed to participate in an interview. In Christchurch three additional individual interviews were conducted with people who were staying at a night shelter but who had not participated in the focus group. Participant identification, consent, and interview location for these interviews followed a similar process as the focus groups. In addition to participants from the focus groups, interviews were also conducted with homeless people who the research team met on the streets. The researchers first explained the project objectives and invited potential participants to contribute. Consent was given verbally and a NZD 20.00 supermarket voucher for their time was given. These interviews took place on the street where the people were located. In total, nine interviews were conducted with individuals who were or had been homeless, six in Wellington and three in Christchurch. Eight of the interviewees were males in their 20s to $50 \mathrm{~s}$ and one woman aged around 50 years old. They were interviewed in diverse settings from the street where they were "hustling" (begging), the night shelters where they stayed, or at service organizations for homeless people. These interviews were geared towards identifying the finegrained details of their everyday lives as well as their personal experiences in dealing with natural and other hazards.

Both the focus groups and the interviews with homeless people and organizations were audio recorded and transcribed by the members of the project team. The interviews that were conducted with people on the streets were not audio-recorded but extensive notes were taken. Prior to field research a full ethics application was approved by the University of Auckland Human Ethics Committee, which covered all aspects of the research design including recruitment processes, informed consent, and reimbursement of time.

Empirical data from the semistructured interviews and focus groups were then thematically analyzed across three fields: (1) which hazards prove most significant for 
homeless people; (2) the relationship between their precarity and large as well as everyday hazards; and (3) the intersections between power and precarity. The data analysis followed Braun and Clarke's (2006) framework and took place over a 2-day workshop. This involved close reading of the transcripts and detailed field notes to identify significant contextual and experiential themes within the three fields mentioned above. Categories of contextual (that is, local government bylaws, health service availability) and experiential (that is, everyday and natural hazards) were coded and then analyzed for key themes. Three main themes were identified: homeless people's experience of natural hazards, the everyday hazards of homelessness, and finally the intersections between vulnerability to hazards, the operation of power, and life states of persistent precarity. We present these three themes in the following two sections. Throughout these sections pseudonyms have been used to protect the identity of participants.

\section{The Everyday Hazards of Homelessness and the Disaster of Everyday Life}

Homeless people's ranking of hazards during focus groups in Wellington and Christchurch both led to the same outcome: natural hazards proved less significant than the nonnatural hazards of everyday life. In Wellington, the main threats identified by participants included changes in government policies, limited financial resources, lack of sleep and food, illnesses, and intimidation and violence. The only prominent natural threat that homeless people identified was cold during winter; then came earthquakes, tsunami, and volcanic eruptions down the list of hazards. Similar trends emerged in Christchurch where hygiene and health issues, including depression and boredom, topped the list of hazards, followed by lack of sleep, alcohol and drugs, and changes in government policies. Natural hazards, especially snowstorms, earthquakes, and tsunami were less significant to homeless people's lives. Interviews eventually allowed to uncover why these hazards are more or less threatening for homeless people.

Most of the non-natural hazards are closely linked to each other and underpinned by financial insecurity and government policies. They all relate to homeless people's everyday well-being. Financial insecurity indeed has significant adverse impact for their daily struggle for survival and in obtaining food, shelter, and health services. Despite their urgent need for financial assistance people can wait up to 3 months for income support from the responsible government agency-Work and Income New Zealand (WINZ). It is thus an everyday challenge to sustain food needs and locate and safely occupy somewhere to sleep. For those who sleep rough it is hard to find sleeping spaces in city centers that are away from road traffic and partygoers, while in night shelters people sleep in close proximity to each other, which can led to disrupted sleep. Sleep deprivation is also a symptom of other hazards including harassment. Severe sleep deprivation is a hazard that can have both physical and mental health implications (Dinges 1992).

According to a spokesperson from one night shelter, illnesses and other health concerns are "the biggest hazard of being homeless" and this was reiterated by many participants. Homeless people are highly vulnerable to a range of physical health problems from common colds to dental problems, liver disease to malnutrition (Hodgetts et al. 2007). However, our participants emphasized that accessing everyday health care is difficult due to cost and the limited number of facilities specifically servicing the needs of those living without shelter. The ability to recuperate from a physical illness is also problematic because people have no permanent place to rest. For instance, Susan is homeless in Christchurch and is staying at a night shelter for women. Night shelters in New Zealand are closed during the day due to staffing and funding constraints so at 8 a.m., Susan and the other women leave the shelter and are unable to return until 5 p.m. When Susan had a cold and chest infection during winter, her recovery time was far longer than it should have been from having nowhere warm and quiet to rest and sleep during the day. Her mental health suffered and she experienced anxiety and what she referred to as a "mental breakdown" from the stress of being ill with nowhere to go.

As for Simon, who is homeless and has a history of alcohol and substance use, the "biggest hazard to everyday life is often drugs and alcohol," a hazard directly related to health concerns. Substance use and addiction can be a contributing factor that catalyzes a person into homelessness and for rough sleepers and those in night shelters, their vulnerability to continued drug and alcohol use is high. Homeless people's financial desperation and constant presence in the city also make them vulnerable to pressure from gangs to sell drugs on their behalf. Associations with drugs and drug culture are part of everyday life for many homeless and this association can be one of seller, user, and victim of drug crime or a combination.

Substance use and abuse can be closely linked to boredom, and a number of participants spoke about how they feel their vulnerability to seeking drugs and doing crime may be aggravated by boredom, which scholars have also associated to trauma associated with homelessness (Chambers et al. 2014; O'Neill 2017) and globalization since those without a job, a home, and money to spend cannot fully participate in our increasingly consumptive societies. For homeless people boredom arises from people having nowhere to go and nothing to do. However, it also 
has to do with the availability of services and public spaces during the day. People try to occupy their time in shopping centers and public libraries but can feel socially stigmatized and embarrassed if they have been unable to shower or wash their clothes or can be asked to leave if they appear to be loitering or sleeping. Some shelters provide day programs and others provide activity centers for vulnerable individuals. However, while open-access centers are important for homeless people, there are very few and many are struggling to keep their services going.

Very few of our participants spontaneously chose to talk about natural hazards and when they did it was often in relation to the foregoing everyday struggle to sustain their shelter, food, and health needs. For those who did, they considered harsh weather conditions such as intense rain and cold to be the most significant natural hazards they face. As we were preparing this article it was reported in the national media that a homeless man died in Auckland during a seasonal polar blast that plummeted temperatures. He was found dead "huddled under his sleeping bag at the back of a church" (Harris 2017). Beyond such extreme instances, a major challenge of sleeping rough is the ability to get dry after getting wet. This not only refers to homeless people and their clothes but also to their belongings that they often carry with them at all times.

While being wet and cold is not always life threatening it does make homeless people highly vulnerable to weather-related illnesses such as bronchitis and pneumonia. Indeed, such illnesses are very common among homeless people in winter according to staff of night shelters. Wet and cold weather conditions combine with the cost of blankets and warm clothing, and the task of keeping these dry and in their possession due to theft poses a serious hazard for homeless people. In times of wet and cold weather conditions, some homeless people resort to trespassing into abandoned buildings to find shelter. Adverse weather conditions can also lead to a shortage of beds in night shelters. In Wellington for example, the number of people seeking a bed in night shelters frequently exceeds their availability, especially in times of bad weather.

Many of homeless people who participated in our focus groups and interviews had given little thought to the possibility of larger and rare natural hazards. Some respondents actually felt they would be less vulnerable than the housed population in regards to some hazards such as major fires because they would not be trapped inside buildings. Among those who did feel concerned about large-scale natural hazards, earthquakes were most frequently talked about. This is perhaps not surprising given the devastating 2010-2011 earthquakes in Christchurch and that some homeless people had directly experienced them. For example, John lived in Christchurch when the
2011 earthquake struck and although he has stayed in less earthquake-prone cities across the country since then, he still holds an ongoing fear that an earthquake will strike and he will be vulnerable to buildings and panels of glass falling. Another concern to homeless people is that they do not have the financial resources or physical space and capacity to hold stocks of food and other necessities should a large-scale event strike. John, who is on daily medication, worries that in the event of an earthquake he will not be able to access water to take his prescribed medicine.

Homeless people are not only vulnerable when large hazards occur but also to secondary impacts that manifest in cities that are prone to such hazards. In Wellington there are a number of buildings that have been declared earthquake prone, which are not legally allowed to be inhabited. However, these buildings often become temporary shelter for homeless people as they seek somewhere quiet and dry to spend time and sleep. This was also the case in Christchurch where many people who were rough sleepers before the 2010-2011 earthquakes sought shelter in abandoned buildings that were deemed uninhabitable and fragile. Some of these buildings are older wooden buildings that are at risk of fire, especially if the people are preparing fires inside to create warmth.

A less obvious dimension of homeless people's vulnerability to natural hazards is the possibility of the public places they occupy being usurped for disaster relief efforts. For example, in Christchurch, one of the city's parks where homeless people sleep was used as an emergency center during the 2011 earthquake. While this may appear to be beneficial for homeless people, in that emergency services were located close to where they stay, in the context of a social group who can feel wary of official agencies, they could feel ostracized and displaced as actually suggested by Civil Defence Emergency Management officers in Wellington.

Connecting with the agencies that normally support them, especially if their services are disrupted, is another concern for homeless people should a large and rare natural hazard strike. During an earthquake that struck Wellington in 2013, a local charity the Downtown City Ministry (DCM), had to temporarily move their services to the city's night shelter and in a subsequent earthquake utilized the City Council's buildings. What aided DCM to communicate to homeless people at these times was the Wellington Homeless Advocates for Whānau, a support group formed by former homeless people who developed a plan for directing homeless people to a designated meeting point. Local efforts such as this example draw on existing and trusted networks and have important immediate impact in times of natural hazards.

Large and rare natural hazards such as earthquakes also adversely impact the housing market, which makes it all 
the more difficult for the financially insecure to access housing. In Christchurch, rents have escalated since the 2011 earthquake due to decreased housing stock and increased demand, especially within the low cost housing market (Ministry of Business, Innovation and Employment 2013). Average rent increased in the city by NZD 92.00 per week after the earthquake and given that the basic government income support is only NZD 138.00 per week, the knock-on effects of the earthquake in terms of housing has inevitably increased the precarity of homeless people in securing accommodation. Furthermore, in Wellington a number of government social housing properties have been closed because they do not comply with earthquake strengthening. While efforts are currently underway to upgrade social housing in the city, according to the DCM, this situation has exacerbated the waiting list for social housing and contributed to homelessness.

The foregoing paragraphs show that homeless people are vulnerable to the impact of natural hazards. Nonetheless, most of our participants rather wanted to focus on the everyday hazards they experience and that impact their lives and of much more significance to them. Overcoming these is often a matter of survival unlike for better-housed people for whom threats to life may refer to large natural hazards. Perception of risk is therefore a matter of temporal significance rather than a question of magnitude of the hazard (Wisner 1993; Gaillard 2010). For homeless people, everyday life mirrors all characteristics of a disaster defined as both a situation and process involving a hazardous event, which has consequences in terms of damage, livelihoods disruption, and/or casualties (Wisner et al. 2012). Financial insecurity and its impact on access to shelter as well as health and substance use therefore constitute everyday hazards for vulnerable homeless people whose very survival is at stake on a daily basis. The significance of these threats to everyday life overshadows the possible effects of large and rare natural hazards. For most of our participants, everyday life is a disaster in itself. Vulnerability to natural hazards can therefore not be dissociated from the precarity of life that is deeply entrenched in the unequal distribution of power within society.

\section{Vulnerability, Persistent Precarity, Power, and the Disaster of Everyday Life}

The foregoing evidence from New Zealand shows that homeless people's vulnerability in facing both natural and everyday hazards similarly manifests in them living in a state of persistent precarity at the spatial, economic, social, and political margins of society. As Wisner (1998, p. 29) suggests, "homelessness bundles together most of the challenges and opportunities associated with vulnerability: lack of access, isolation, lack of resources" or the expression of the lack of direct power to control one's everyday life. By "persistent precarity" we thus mean states of being where people are forced to live in volatile and unstable lifeworlds that continue to exist over a sustained period and that make everyday life a disaster (Vickery 2017).

The everyday hazards our homeless informants experience are not isolated and indeed combine to reinforce the persistent nature of precarity and vulnerability. They are formed from complex intersections between a diverse set of hazards that manifest in and from a variety of domains: political, social, economic, and physical. For example, for most homeless people who participated in our interviews and focus groups, sleep deprivation can be a consequence of adverse weather conditions, noise, or forced movement. The latter has resulted in many homeless people not trusting private security guards or the police and therefore unlikely to seek their assistance in time of need, including in dealing with natural hazards. Moreover, homeless peoples' exposure and experiences of both natural and everyday hazards, individually and combined, can deepen their already persistent precarity.

However, as mentioned earlier, precarity does not begin for our homeless informants at the time they find themselves without shelter: depression, mental illness, substance addiction, and conviction and imprisonment are contributing factors to homelessness and the likelihood of the occurrence and/or recurrence of these once a person is homeless is high both in New Zealand and elsewhere in the world (Rossi 1991; Snow and Anderson 1993; Groot 2010). Thus, homeless people lack direct power to control their everyday life and exist in a state of persistent precarity, vulnerability, and marginalization both in facing everyday and natural hazards. Understanding the root causes of persistent precarity and associated vulnerability to the disaster of everyday life henceforth requires to look beyond the spectrum of these hazards and unpack how the broader distribution of power in society shapes homeless people's precarious lives (Wisner 1998; Walters and Gaillard 2014).

Homeless people's vulnerability and associated precarity operates across their life-course rather than in a single time and context. While a person who is experiencing homelessness is clearly precarious, their precarious lifeworlds begin before, and are catalysts for, people becoming homeless. Ultimately, precarious lifeworlds and lack of direct power can restrict a person's overall well-being and prevent them from obtaining sustainable resources and housing arrangements that matter in facing both everyday and natural hazards. Thus persistent precarity is an enduring condition for those living at the margins of society. In New Zealand, as elsewhere in the world (Rossi 1991; Jencks 1994), this condition is constructed and 
perpetuated by the broader operation of power by the state and other actors of the neoliberal urban environment who control both the housing market and the provision of welfare services. For homeless people the effect of this is their inability to sustain their daily needs and protect themselves when faced with both everyday and natural hazards (Wisner 1998; Walters and Gaillard 2014).

Among our research participants people had experienced one or more of the following situations prior to becoming homeless: violent childhoods and home environments, introduction to drugs and alcohol in their early lives, exposure to crime and/or gangs, personal mental health, loss of job, and family break ups. These factors, in isolation or combination, alongside a lack of direct power to control their life circumstances, are catalysts for people becoming homeless (Rossi 1991; Snow and Anderson 1993; Jencks 1994). The lack of direct power people experience prior to becoming homeless is operationalized at multiple levels and through the broader power relations in society that affect, and constrain, their choices and decisions in everyday life as well as when dealing with large and rare natural hazards (for example, between parents and children, among peers and within social worlds, and in the failure of adequate social protections and services). The inability of individuals to actualize power therefore manifests from social and political structures where the vulnerable are overlooked, victimized, and marginalized (Wolch and Dear 1993; Laurenson and Collins 2006).

Homeless people's ability to access secure housing and deal with both everyday and natural hazards is also affected by existing social and political structures and how power is constrained and misallocated within them (Wolch and Dear 1993; Wisner 1998; Mitchell 2003). Many of the hazards homeless people face, as well as their vulnerability to them, are conditioned by state actors and in policy decisions on government priorities and spending. As a spokesperson from the Wellington City Council stated, it is "those decisions that government makes around benefits, the hospitals, mental health-all those things are more hazardous than anything [for homeless people]." Insufficient social safety nets for people experiencing job instability, inadequate public health services for the poor, discriminatory policing and urban by-laws, and reductions in funding and scaling-down or closure of drop-in centers all pose serious threats to homeless people and their ability to meet their daily needs, secure adequate housing, and achieve a state of well-being. These have cascading effects when natural hazards strike.

The prevalence and indeed increasing number of people who are homeless in New Zealand and the persistent precarity these individuals endure point to the failure of the state to guarantee fundamental human rights for some of the country's most vulnerable citizens, including the right to claim and access adequate shelter, health, and dignity. John, one of the research participants who was previously homeless in Christchurch and is currently precariously housed in Wellington, made this point when he stated: "People have rights and the government is not meeting these rights. It is the government's role to make sure that all people can be full citizens." To be a full citizen requires the state and state actors to recognize individuals and groups who are vulnerable to persistent precarity and to take the necessary steps to ensure their rights to claim and access sustainable resources are both realized and protected, including in DRR.

\section{Homeless People in Policies and Practices for Reducing the Risk of Disaster}

The foregoing section has emphasized that state policies can push homeless people to the margin of society and contribute to depriving them of access to resources, including housing and health care that are available to those with more resources and power. This is also reflected in DRR.

Historically, DRR in New Zealand has been designed from the perspective of large natural hazards against which military tactics should be deployed. It has long consisted in fostering preparedness and responding to disasters through top-down and command-and-control initiatives led by local councils and supported by Civil Defence Emergency Management (CDEM) groups, the police, fire brigades, and the army (Jensen 1998). However, since the early 2000s, more proactive approaches have been designed to prevent hazards and disasters, reduce people's vulnerability, and increase their capacities. In this perspective, the most recent National Civil Defence Emergency Management Plan of 2015 is meant to enable rather than prescribe any particular initiatives (New Zealand Government 2015) with the implementation and regulations of such initiatives transferred to local government authorities.

In this context, local CDEM groups are in charge of early warning and preparedness, while councils look after building reinforcement as well as land-use planning, and the Earthquake Commission provides insurance (Glavovic et al. 2010). These organizations are the dominant stakeholders of DRR in New Zealand. Yet, numerous civil society organizations, including nongovernment organizations, the New Zealand Red Cross, and community groups, are also involved in addressing people's vulnerability and enhancing their capacities (Gaillard and Hill 2016). With the increasing involvement of civil society organizations some minority groups, such as people with disabilities, children, and older people are now being considered in 
DRR in New Zealand. However, as elsewhere in the world, the fate of the poor who are precariously sheltered has received very limited attention so far.

One of the main challenges here is for local CDEM groups and the agencies they partner with such as the Police and Fire Brigade to develop positive relationships and trust between themselves and homeless people so that a meaningful dialogue between stakeholders, including homeless people can be established. Some progress is being made in this area but it is still in the very early stages. For instance, in Wellington the soup kitchen and night shelter are carrying out discussions around emergency planning with the local CDEM group and in one of the major social housing complexes (Arlington), community groups are working with the council on an emergency plan. The night shelter in Wellington has also taken the initiative of preparing emergency parcels for homeless people, including bottled water. One of the study respondents who is currently residing in this complex, is part of this group, which demonstrates an effort and willingness to engage and actively include those housed in these complexes. Such initiatives confirm emerging observations worldwide that urban policies are not necessarily all hostile to homeless people and those who are precariously sheltered and that opportunities exist for inclusiveness (DeVerteuil 2006; Cloke et al. 2010).

Establishing such a dialogue between stakeholders, including homeless people themselves, is essential for better understanding the needs and securing the resources required by homeless people when faced with natural hazards in the unique context of the persistent precarity of their everyday life. While there are locations that homeless people use frequently such as parks or church grounds for sleeping or socializing, support centers and services, and footpaths for "hustling" (begging), homeless people can also be transient and mobile within a city and seek quiet, discrete, and out of the way spots to rest. This means their location can be unknown, even to those within their network, which creates difficulties for communicating to them about impending natural hazards in sufficient time. For example, tsunamis are part of Christchurch's risk profile but the warning time can vary quite significantly from $10 \mathrm{~min}$ for a local tsunami to $12 \mathrm{~h}$ for a distant one. While it may be possible to evacuate the city's population including homeless people in the event of a tsunami originating at a distance, for a localized one communicating to those who may not be connected to the media, are staying in discrete locations and prohibited buildings, or who have no door to knock on, informing them about the need to evacuate is significantly less feasible. This is a limitation associated with current CDEM strategies that focus largely on "communities" that are place-based rather than the vulnerably dispersed such as homeless people.
Furthermore, providing homeless people with the ability to contribute to DRR is challenging in the context of current policy and governance arrangements. Despite genuine interest and commitment on the side of some stakeholders, the legacy of technocratic and command-and-control approaches geared towards natural hazards, especially large ones, does not give much space for considering the specific needs and resources of homeless people whose prime concerns are everyday hazards and the disaster of their everyday life. Fostering inclusive DRR requires rethinking how power is ultimately shared within society, public policy in general and DRR in particular.

\section{From Precarity to Empowerment}

Being homeless in cities that are prone to natural hazards acts as a ratchet process of marginalization and vulnerability, that manifest in persistent precarity and the disaster of everyday life (Wisner 1998; Vickery 2017). Better understanding these issues calls for a transfer of power (empowerment), towards homeless people so that they gain greater control on the processes and events that shape their lives (Rapapport 1984). However, sharing power requires an appropriate social and political environment that can only happen should power structures and relations within society be transformed (Hickey and Mohan 2005). There is therefore an imperative to provide people whose identity is often socially and politically neglected by existing governance structures with the legitimate and legal ability to claim their rights and gain access to resources that are available to other people in society. Fostering homeless people's participation in designing and implementing DRR programs and projects that are cognizant of their needs and resources is a required step towards inclusive DRR. However, genuine participation can only happen (beyond the rhetoric of tokenistic participation) if appropriate governance spaces exist to allow for the transfer of power to homeless people to make decisions that will affect their lives and well-being.

Genuine participation to access power and resourcesso-called bottom-up approaches to DRR-can only occur should there be enough external willingness and intervention, that is, from the top down, to share power within existing structures. Disaster risk reduction policies and practices are only a part of reducing the risk of disaster for homeless people that, as this article has shown, requires going beyond natural hazards, preparedness, and response to disasters. It has to address the root causes of homeless people's precarious lives and vulnerability, especially their vulnerability to everyday hazards and the disaster of everyday life that ultimately underpins homeless people's ability to face less frequent natural hazards. Disaster risk 
reduction therefore has to be embedded within policies geared towards addressing structural causes of marginalization, including housing policies, poverty reduction strategies, and public health programs. These are essential to alleviate homeless people's state of persistent precarity and by extension their vulnerability to natural hazards (Wisner 1998; Walters and Gaillard 2014). Ultimately, this requires integrating persistent precarity into DRR and DRR into everyday social protection.

Acknowledgements This study was supported by a grant from the University of Auckland through its Faculty Research Development Fund (No. 3706764). The authors are grateful to Shiloh Groot (The University of Auckland) and Robin Kearns (The University of Auckland) for their comments and suggestions on early drafts of this article.

Open Access This article is distributed under the terms of the Creative Commons Attribution 4.0 International License (http://crea tivecommons.org/licenses/by/4.0/), which permits unrestricted use, distribution, and reproduction in any medium, provided you give appropriate credit to the original author(s) and the source, provide a link to the Creative Commons license, and indicate if changes were made.

\section{References}

Amore, K., H. Viggers, M.G. Baker, and P. Howden-Chapman. 2013. Severe housing deprivation: The problem and its measurement. Official Statistics Research Series 6. Wellington: Statistics New Zealand.

Baird, A., P. O'Keefe, K. Westgate, and B. Wisner. 1975. Towards an explanation and reduction of disaster proneness. Occasional paper No. 11. Disaster Research Unit. Bradford: University of Bradford.

Blaikie, P., and H. Brookfield. 1987. Land degradation and society. London: Methuen.

Braun, V., and V. Clarke. 2006. Using thematic analysis in psychology. Qualitative Research in Psychology 3(2): 77-101.

Butler, J. 2004. Precarious life: The power of mourning and violence. London: Verso.

Chambers, C., S. Chiu, A.N. Scott, G. Tolomiczenko, D.A. Redelmeier, W. Levinson, and S.W. Hwang. 2014. Factors associated with poor mental health status among homeless women with and without dependent children. Community Mental Health Journal 50(5): 553-559.

Clegg, S.R. 1989. Frameworks of power. London: Sage.

Cloke, P., J. May, and S. Johnsen. 2010. Swept up lives? Reenvisioning the homeless city. Chichester: Wiley-Blackwell.

Collins, D. 2010. Homelessness in Canada and New Zealand: A comparative perspective on numbers and policy response. Urban Geography 31(7): 932-952.

Collins, D., and R. Kearns. 2007. Geographies of homelessness in New Zealand. Parity 20(9): 11-12.

Cusack, L., A. van Loon, D. Kralik, P. Arbon, and S. Gilbert. 2013. Extreme weather-related health needs of people who are homeless. Australian Journal of Primary Health 19: 250-255.

DeVerteuil, G. 2006. The local state and homeless shelters: Beyond revanchism? Cities 23(2): 109-120.

Dinges, D. 1992. Probing the limits of functional capability: The effects of sleep loss on short-duration tasks. In Sleep, arousal and performance, ed. R. Broughton, and R. Ogilvie, 176-188. New York: Birkhauser-Boston.

Drabek, T.E. 1999. Disaster evacuation response by tourists and other types of transients. International Journal of Public Administration 22(5): 655-677.

Edgington, S. 2009. Disaster planning for people experiencing homelessness. Nashville: National Health Care for the Homeless Council.

Every, D., and K. Thomspson. 2014. Disaster resilience: Can the homeless afford it? Australian Journal of Emergency Management 29(3): 52-56.

Every, D., and R. Richardson. 2017. Building the severe weather and disaster resilience of the homeless community. Adelaide and Melbourne: Central Queensland University and Australian Red Cross.

Gaillard, J.C. 2010. Vulnerability, capacity, and resilience: Perspectives for climate and development policy. Journal of International Development 22(2): 218-232.

Gaillard, J.C., and M. Hill. 2016. Disaster risk reduction. In State of New Zealand report-Let's prepare for Habitat III, ed. D. Reeves, 55-56. Auckland: The University of Auckland.

Glavovic, B.C., W.S.A. Saunders, and J.S. Becker. 2010. Land-use planning for natural hazards in New Zealand: The setting, barriers, "burning issues" and priority actions. Natural Hazards 54(3): 679-706.

GNDR (Global Network for Disaster Reduction). 2015. Everyday disasters and everyday heroes: How Frontline finds out from local people what threats they face. London: Global Network for Disaster Reduction.

Groot, S.A.M. 2010. Contextualizing street homelessness in New Zealand: A case study approach. Ph.D. thesis, The University of Waikato, Hamilton.

Groot, S.A.M., N. Tassell-Matamua, C. van Ommen, and B. MastersAwatere. 2017. Precarity: Uncertain, insecure and unequal lives in Aoetaroa New Zealand. Auckland: Massey University Press.

Harris, S. 2017. Homeless man found dead outside Manurewa Methodist Church. New Zealand Herald, 13 July 2017. http:// www.nzherald.co.nz/nz/news/article.cfm?c_id=1\&objectid= 11890266. Accessed 14 July 2017.

Hartmann, B., and J.K. Boyce. 1983. A quiet violence: View from a Bangladesh village. London: Zed Books.

Haugaard, M. 2002. Power: A reader. Manchester: Manchester University Press.

Hewitt, K. 2007. Preventable disasters: Addressing social vulnerability, institutional risk, and civil ethics. Geographische Rundschau International Edition 3: 43-52.

Hickey, S., and G. Mohan (ed.). 2005. Participation: From tyranny to transformation? London: Zed Books.

Hodgetts, D., A. Radley, K. Chamberlain, and A. Hodgetts. 2007. Health inequalities and homelessness: Considering material, spatial and relational dimensions. Journal of Health Psychology 12(5): 709-725.

Hodgetts, D., O. Stolte, L.W. Nikora, and S. Groot. 2012. Drifting along or dropping into homelessness: A class analysis of responses to homelessness. Antipode 44(4): 1209-1226.

Jencks, C. 1994. The homeless. Cambridge: Harvard University Press.

Jensen, S. 1998. New Zealand's emergency management system and the role of local government. Australian Journal of Emergency Management 13(1): 27-29.

Kearns, R.A., C.J. Smith, and M.W. Abbott. 1992. The stress of incipient homelessness. Housing Studies 7(4): 280-298.

Laurenson, P., and D. Collins. 2006. Towards inclusion: Local government, public space and homelessness in New Zealand. New Zealand Geographer 62(3): 185-195. 
Laurenson, P., and D. Collins. 2007. Beyond punitive regulation? New Zealand local governments' responses to homelessness. Antipode 39(4): 649-667.

Lavell, A. 2000. A decade of disasters: Conceptual and practical lessons in Latin America (1990-1999) (Desastres durante una década: Lecciones y avances conceptuales y prácticos en América Latina (1990-1999)). Anuario Política y Social de América Latina 3: 1-34.

Liamputtong, P. 2007. Researching the vulnerable: A guide to sensitive research methods. London: Sage.

Maskrey, A. 1989. Disaster mitigation: A community based approach. Development Guidelines No. 3. Oxford: Oxfam.

Ministry of Business, Innovation and Employment. 2013. Housing pressures in Christchurch: A summary of the evidence/2013. Wellington: Ministry of Business, Innovation and Employment. https://www.mbie.govt.nz/publications-research/research/.../ christchurch-housing-report.pdf. Accessed 13 July 2017.

Mitchell, D. 2003. The right to the city: Social justice and the fight for public space. New York: Guilford Press.

New Zealand Government. 2015. National civil defence emergency management plan 2015. Wellington: New Zealand Government.

O'Keefe, P., K. Westgate, and B. Wisner. 1976. Taking the naturalness out of natural disasters. Nature 260(5552): 566-567.

O'Neill, B. 2017. The space of boredom: Homelessness in the slowing global order. Durham: Duke University Press.

Phillips, B.D. 1996. Creating, sustaining, and losing place: Homelessness in the context of disaster. Humanity and Society 20(1): 94-101.

Phillips, B.D. 1998. Sheltering and housing of low-income and minority groups in Santa Cruz County after the Loma Prieta earthquake. In The Loma Prieta, California, Earthquake of October 17, 1989-Recovery, mitigation and reconstruction, ed. J.M. Nigg, D17-D28. Washington: US Geological Survey.

Phillips, B.D. 2014. Qualitative disaster research. New York: Oxford University Press.

Potter, S.H., J.S. Becker, D.M. Johnston, and K.P. Rossiter. 2015. An overview of the impacts of the 2010-2011 Canterbury earthquakes. International Journal of Disaster Risk Reduction 14(1): 6-14.

Rapapport, J. 1984. Studies in empowerment. Prevention in Human Services 3(2-3): 1-7.

Richards, S. 2009. Homelessness in Aotearoa: Issues and recommendations. Wellington: New Zealand Coalition to End Homelessness.

Rossi, P.H. 1991. Down and out in America: The origins of homelessness. Chicago: University of Chicago Press.

Settembrino, M.R. 2013. The effects of Hurricane Sandy on the homeless in New Jersey. Quick Response Research Report No. 239. Boulder: Natural Hazards Center.

Settembrino, M.R. 2015. Vulnerable yet resilient: Homelessness and disaster response in the United States. Natural Hazards Observer 40(2): 4-9.

Settembrino, M.R. 2016. Hurricane Sandy's impact on the predisaster homeless and homeless shelter services in New Jersey. Journal of Emergency Management 14(1): 7-16.
Snow, D.A., and L. Anderson. 1993. Down on their luck: A study of homeless street people. Berkeley: University of California Press.

Statistics New Zealand. 2009. New Zealand definition of homelessness. Wellington: Statistics New Zealand.

Statistics New Zealand. 2014. 2013 Census quickStats about housing. Wellington: Statistics New Zealand.

Stevenson, J., J. Becker, N. Cradock-Henry, S. Johal, D. Johnston, C. Orchiston, and E. Seville. 2017. Economic and social reconnaissance: Kaikōura earthquake 2016. Bulletin of the New Zealand Society for Earthquake Engineering 50(2): 343-351.

Sundareswaran, M., A. Ghazzawi, and T.L. O'Sullivan. 2015. Upstream disaster management to support people experiencing homelessness. PLOS Currents Disasters. https://doi.org/10.1371/ currents.dis.95f6b76789ce910bae08b6dc1f252c7d.

UNISDR (United Nations International Strategy for Disaster Reduction). 2015. Sendai framework for disaster risk reduction. Geneva: United Nations International Strategy for Disaster Reduction.

Vickery, J. 2015. "Every day is a disaster"-Understanding the challenges faced by homeless service organizations in disaster planning and response. Natural Hazards Observer 40(2): 10-13.

Vickery, J. 2017. Everyday is a disaster: Homelessness and the 2013 Colorado floods. Ph.D. thesis, University of Colorado, Boulder.

Vickery, J. 2018. Using an intersectional approach to advance understanding of homeless persons' vulnerability to disaster. Environmental Sociology 4(1): 136-147.

Waite, L. 2009. A place and space for a critical geography of precarity? Geography Compass (3)1: 412-433.

Walters, V., and J.C. Gaillard. 2014. Disaster risk at the margins: Homelessness, vulnerability and hazards. Habitat International 44: 211-219.

Watts, M.J., and H.G. Bohle. 1993. The space of vulnerability: The causal structure of hunger and famine. Progress in Human Geography 17(1): 43-67.

Winchester, P. 1992. Power, choice and vulnerability: A case study in disaster mismanagement in South India, 1977-1988. London: James and James Science Publishers.

Wisner, B. 1993. Disaster vulnerability: Scale, power, and daily life. Geojournal 30(2): 127-140.

Wisner, B. 1998. Marginality and vulnerability: Why the homeless of Tokyo don't "count" in disaster preparations. Applied Geography 18(1): 25-33.

Wisner, B., and J.C. Gaillard. 2009. An introduction to neglected disasters. Jàmbá: Journal of Disaster Risk Studies 2(3): 151-158.

Wisner, B., P. Blaikie, T. Cannon, and I. Davis. 2004. At risk: Natural hazards, people's vulnerability, and disasters, 2nd edn. London: Routledge.

Wisner, B., J.C. Gaillard, and I. Kelman. 2012. Handbook of hazards and disaster risk reduction. Abingdon: Routledge.

Wolch, J., and M. Dear. 1993. Malign neglect: Homelessness in an American city. San Francisco: Jossey Bass. 